\title{
Useful chatbot experience provides technological satisfaction: An emerging market perspective
}

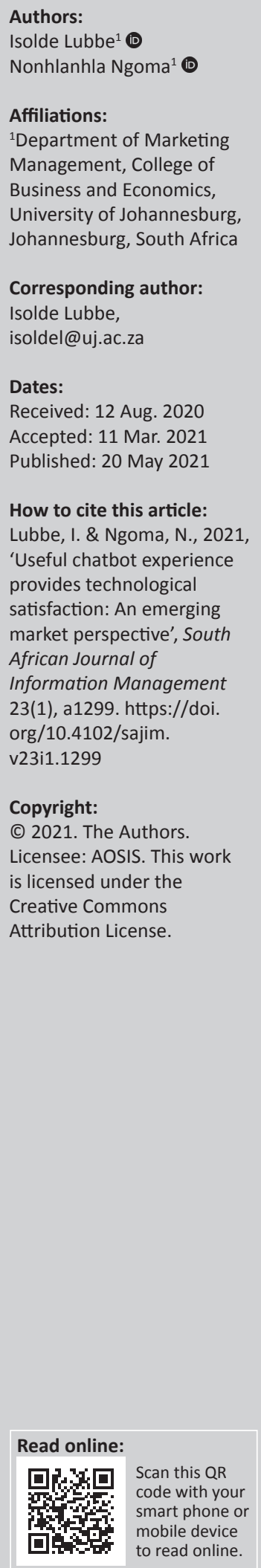

Background: Chatbots have revolutionised marketing and specifically customer services by delivering 24/7 customer care. This technology saves resources and time, whilst enhancing customer experience that has become a critical differentiating factor in an increasing competitive and hyperconnected landscape.

Objectives: This research examined how perceived ease of use (PEOU), perceived playfulness (PP) and perceived usefulness (PU) of chatbots influence customer experience and how these experiences influence users' satisfaction in an emerging market context.

Method: A self-administered questionnaire was distributed to 333 South African millennials and subjected to exploratory factor analysis and multiple regression analysis to test the proposed hypotheses.

Results: The results indicate that all the hypotheses suggested have been positive and significant. Whilst experience significantly predicted satisfaction, it is worth noting that PU was the strongest predictor of experience.

Conclusion: Marketers should devote time, money and recourses in developing and incorporating self-service technologies, such as chatbots, that are useful for their marketing strategies that will enhance customer experience.

Keywords: chatbots; technology acceptance antecedents; self-service technology; self-service technology experience; self-service technology satisfaction.

\section{Introduction}

Innovative solutions, such as providing customers with personalised experiences through the application of chatbots, present the following benefits: customer convenience and efficiency, reduced customer service times, increased information, improved productivity and customer satisfaction (Toader et al. 2020).

Chatbots or virtual assistants have changed the marketing landscape with increased automation, omnipresent personal assistance, 24/7 customer service and hyper targeting (KaczorowskaSpychalska 2019:254).

Furthermore, as a self-service technology (SST), chatbots can imitate human conversation via text input, audio input, or both, and are a form of unique natural language processing technology that provides superior accuracy and performance, resulting in increased customer usage and satisfaction (Feine, Morana \& Gnewuch 2019).

The impact of implementing chatbots into a marketing strategy is worth investigating, as it has been predicted that by the year 2020, $85 \%$ of customer exchanges will be handled without human employees (Chatbots Life 2019), whilst 25\% of all organisations will integrate chatbot technology into their customer service (Gartner 2018). Marketers thus have to understand what influences customers' chatbot experience because positive experience will lead to customer satisfaction (De Haan et al. 2018; Djelassi, Diallo \& Zielke 2018). Positive experience can differentiate a brand and satisfied customers are more likely to buy, promote and recommend the brand (Duijst 2017; Hemdi et al. 2016). Current literature explains that customers want to experience flexibility and convenience, whilst avoiding extensive waiting time when interacting with a chatbot (Djelassi et al. 2018). However, to further investigate if this statement is true in an emerging market setting and to determine which technology acceptance factors influence the chatbot experience, the technology acceptance model (TAM) was applied. Chatbots are relatively new to customer service technology (Verma 2019) and adoption of this technology will be affected by certain antecedents 
such as its perceived ease of use (PEOU), perceived usefulness (PU) and perceived playfulness (PP) (Awa, Ojabo \& Emecheta 2015; Davis 1989).

The technology acceptance model has been successfully applied in several chatbot studies: its influence on behavioural intention (Rese, Ganster \& Baier 2020), its impact on chatbots enhancing job performance in Indonesia's hotel industry (Gunawan, Putri \& Meidia 2020) and its influence on chatbots' effectiveness in a learning environment in China (Chen, Widarso \& Sutrisno 2020). Notwithstanding, no evidence in current literature could be found of studies investigating all the TAM's antecedence (PEOU, PU, PP) and their direct influence on chatbot experiences. Although Feine et al. (2019) study examined a chatbot service encounter's effect on satisfaction with sentiment analysis, and Djelassi et al. (2018) studied the relationship between SST experience and SST satisfaction, the mediating role of chatbot experiences between these TAM antecedences and chatbot satisfaction has as yet not been investigated in an emerging market context.

To conclude, the purpose of this study was to establish whether the technology acceptance antecedents suggested by previous quantitative research influence chatbot experience and whether chatbot experience as a mediator influences chatbot satisfaction in an emerging market context. In this study, specifically SST is investigated and not technology as a broad term. Although SST is still a subset of technology, the difference is that SST focuses specifically on the interactions of a customer with the organisation in the absence of a representative of that organisation (Åkesson \& Edvardsson 2018).

\section{Literature review \\ Self-service technologies}

Self-service technology interfaces such as chatbots are altering the way in which customers interact with organisations without human assistance (Davenport et al. 2020).

Such changes are equally true in emerging markets such as South Africa. A study by Ernst \& Young to determine what benefits business will gain from using artificial intelligence (AI), like chatbots, found that $96 \%$ of South Africans said they will gain significant financial benefits. Specifically, as the coronavirus disease 2019 (COVID-19) pandemic has shifted the optimisation of chatbots as a means to interact with customers in a safe and efficient way (Conn 2020).

Banks, as an example, have developed SST features such as SnapScan to make easy payments and facial recognition, fingerprint or voice interaction with chatbots for convenient services (Taulli 2019). Although chatbots are being applied in the emerging market context, such applications are still in their infancy and need to be embraced because customer interactions with chatbots are inevitable (Kayton 2018). Interactions with chatbots can enhance customers' experience; however, only a positive technology experience will encourage customers to accept and use new SST such as the chatbot (Akesson, Edvardsson \& Tronvoll 2014).

\section{Theory grounding the study}

The main theory underpinning this study is the TAM model, including PEOU and PU as developed by Davis (1989) and PP as added by Moon and Kim (2001). This model has become a credible means to explain new technology acceptance and describes the user's behaviour across a wide range of user populations and end-user technologies (Davis 1989; Hsiao \& Tang 2014). The TAM model is also relevant for investigating SST-based acceptance (Dabholkar \& Bagozzi 2002:2) and will therefore be used as the framework for the study.

Chatbots are easy to use (PEOU) because of natural language processing technology (Kar \& Halder 2016) and are becoming useful (PU) to organisations and customers alike, as they are perceived to save time and allow for the deployment of human resource to other areas of the business (Kar \& Halder 2016). Furthermore, playful (PP) interactions with a chatbot result in better experience (Jain et al. 2018). The research question is thus formulated to determine whether chatbot experience provides technology satisfaction in an emerging market context, such as South Africa. Furthermore, TAM is a useful model for the development of the hypotheses behind this research as follows: There is a significant and positive relationship between PEOU (H1), PP (H2) and PU (H3) of chatbots and SST experience of a chatbot interaction. Furthermore, H4 was developed to determine if there is a significant and positive relationship between SST experience and SST satisfaction (Figure 1).

\section{Theoretical model development}

It is argued that the PEOU, playfulness and usefulness of a SST such as a chatbot will influence the customers' experience and as the experience accumulates it may predict the customers' expectations and their judgement of satisfaction will be formed (Bilgihan, Kandampully \& Zhang 2016; Haung \& Liao 2015; Wang, Harris \& Patterson 2013). The SST experience variable was adopted from Akesson et al. (2014) and the SST satisfaction variable was adopted from Lin and Hsieh (2006) both are existing and tested scales. Therefore, the final hypothesis was formulated: There is a significant

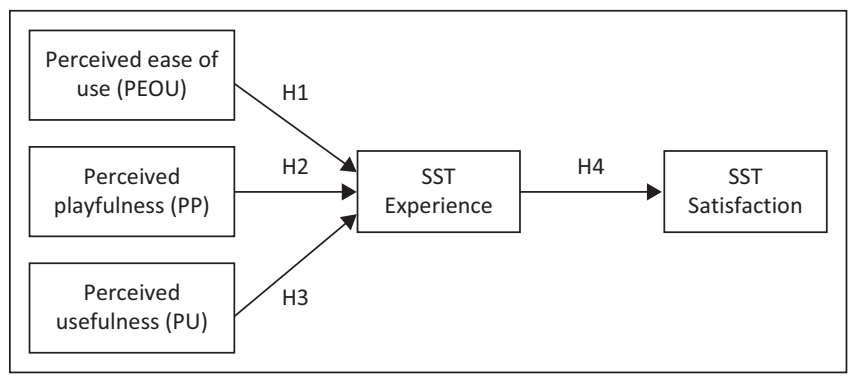

Source: This model is adapted from Davis (1989); Moon and Kim (2001); Akesson, Edvardsson and Tronvoll (2014); and Lin and Hsieh (2006).

SST, self-service technology.

FIGURE 1: Conceptual model portraying the role of SST experience on SST satisfaction. 
and positive relationship between SST experience and SST satisfaction in a chatbot interaction (Figure 1).

\section{Technology acceptance antecedents}

By applying the TAM's antecedents, namely PU, PEOU and $\mathrm{PP}$, it is possible to comprehend and predict users' chatbot behaviour (Moon \& Kim 2001). Perceived usefulness is described by Davis (1989) as the degree to which an individual trusts that through the use of a particular device or system his or her job performance will improve. Past research has shown that $\mathrm{PU}$ is the strongest cognitive determinant of technology acceptance, because customers attach greater importance to whether they will benefit from an innovation (Zarouali et al. 2018). In the context of using a chatbot, Devaney's (2018) study revealed that a useful chatbot can resolve a problem and can provide answers and explanations. Customers are more likely to use chatbots if they save their time by performing tasks more quickly and if they give them more control over the activity they want to perform (Duijst 2017).

Perceived ease of use describes the situation when the use of something, in this case technology, is an effortless experience. The word 'ease' is derived from the word 'easy' and defines something that presents very few difficulties (Davis 1989). Excellent ease of use can decrease the support-costs, by reducing the number of personnel needed (Kar \& Halder 2016). Efficient SST (such as a chatbot) that is understandable and easy to use, decreases the number of complaints, encourages repurchase intension and strengthens the overall customer experience (Abdullah, Ward \& Ahmen 2016; Chatbots Life 2019).

Perceived playfulness, introduced as a construct by Moon and Kim (2001), extends Davis' (1989) TAM model to include a user's enjoyment level. Perceived playfulness is the degree to which 'the activity of using a specific system is perceived to be enjoyable' (Padilla-Melendez, Del Aguila-Obra \& Garrido-Moreno 2013:308).

In addition, Padilla-Melendez et al. (2013) explained that PP is an inherent motivation to use the technology, which is ultimately moulded by the user's experience. Playfulness has been identified as a positive trait in chatbots that links to a better experience and users who are more satisfied (Jain et al. 2018:903).

\section{Self-service experience}

Experience can be defined as the outcome of the interactions between organisations, related systems/processes, service employees and customers' (Bitner et al. 1997:193).

Everything an organisation does contributes to customer experience and customers value experience (Kayton 2018). The number of technology touchpoints between customers and organisations has risen. Customers can access an organisation through many interfaces that are intertwined and any single touchpoint that does not deliver what was expected could have a negative impact on customers' experiences and attitudes (Van de Sand et al. 2020).

Customer experience is an important component of the overall product or service being purchased (Gopalani \& Shick 2011). Its importance is also contributed to the role it plays in customer satisfaction and in turn the possibility of achieving competitive advantage (Mosavi, Sangari \& Keramati 2018). ASST such as a chatbot, enables the customer to perform the service without any contact with service personnel, thus placing the responsibility on the customer by creating inseparability between the customer and the technology (Curran \& Meuter 2005). This interaction will imply a new and unique customer experience as the 'service encounter' is different than in a face-to-face encounter (Djelassi et al. 2018). Many customers report that they feel anxious if the online experience is not flawless (Bilgihan et al. 2014). Thus, whether the customer evaluates the SST experience as either favourable or unfavourable depends on the experience, which could be utilitarian (speed, efficiency) or non-utilitarian (emotional aspects). The customer evaluates these experiences as positive or negative, good or bad, as pleasant or unpleasant or in terms of pleasure and enjoyment (Djelassi et al. 2018). When the evaluation of the technology experience met the customer's expectations, satisfaction is the result (Wang et al. 2013).

Iqbal, Hassan and Habibah (2018) argued that customer experience can be improved by using advanced technology such as SST interface; however, Diaz (2019) and Jain et al. (2018) added that customers tend to be more satisfied with chatbots that provide a good and engaging customer experience. Furthermore, customers expect technologies that are effortless to use, as they positively affect a customers' experience (Bilgihan et al. 2016) whilst playful chatbots enhance experience (Haung \& Liao 2015). Furthermore, a useful chatbot experience will amplify the service, which will ultimately enhance customers' satisfaction with the chatbot (De Haan et al. 2018; Djelassi et al. 2018).

\section{Self-service satisfaction}

Organisations in emerging markets, such as South Africa, are facing economically challenging conditions to survive and prosper, where understanding customers and providing satisfaction, even to the point of exceeding expectations, is crucial (Ryding 2010). In its basic form, customer satisfaction is described as a customer's expectations of the actual performance of the organisation that have been met or exceeded (Oliver 2014).

Customers will evaluate their experience of the service encounter and compare it with what was expected (Rust \& Oliver 1994). Satisfaction is thus an assessment to check whether the products or services fulfil customers' needs and desires (Mkpojiogu \& Hashim 2016). Zeithaml, Bitner and Gremler (2009) concurred with these authors adding that this evaluation of a product or service should meet the customers' requirements, needs and expectations. 
Customers' interaction with a technology, such as a chatbot, goes through the same evaluation process, deciding whether their expectations of the chatbot have been met (De Haan et al. 2018). Hammoud, Bizri and Baba (2018) defined SST satisfaction as the customer's response to using any form of SST. Organisations want satisfied customers as they are an advantage to any organisation and more likely to recommend and promote the product or service (Hemdi et al. 2016). Furthermore, customers who are satisfied with their SST interaction, like a chatbot, tend to buy additional products, are less price sensitive, are less influenced by competitors and are likely to stay loyal for longer (Ryding 2010). What makes chatbots especially special is that they will keep getting better when set up in the right application, meaning that customers' experiences and ultimately their satisfaction can improve over time (Kannan \& Bernoff 2019).

Against the backing provided here, the following model is proposed.

\section{Research methodology and design}

This study is based on an epistemological assumption, as further knowledge about customers' interactions with chatbots was explored, thus adding to existing knowledge (Saunders, Lewis \& Thornhill 2016).

Relationships between variables in this SST setting were investigated in an emerging market (South Africa) context that has, to date, not been investigated. A positivism research philosophy was used by applying a quantitative data collection method that is observable and deductive with a relatively large sample, in this case 333 respondents (Saunders et al. 2016). A descriptive research approach was followed, with the main objective being to describe market characteristic or function (Malhotra 2012).

Information was collected with a previously piloted online questionnaire sent via selected social media platforms such as Facebook and Instagram to 18- to 35-year-old adults, who are millennials (Ahn, Lee \& Lee 2020) residing in South Africa, specifically in Gauteng province. South Africa has over 14 million millennials, making up approximately $27 \%$ of the population (Bizcommunity 2018). The entire population had access to a smart device and/or the Internet and had interacted with a chatbot before. The screening questions addressed these issues of accessibility and actual interaction with a chatbot. Respondents who have not met the age or chatbot interaction criteria were removed for further analysis. A convenience, non-probability sampling technique, without replacement, was selected for this study and respondents were approached to complete a structured questionnaire. Snowballing was also employed, as the research team asked respondents to identify friends or other individuals who they knew to be of similar age and who had interacted with a chatbot before.

The questionnaire was structured according to the chosen variables of the proposed model (Figure 1). Section A obtained information about the technological background of the respondents and included the screening questions. Section B consisted of demographic questions, whilst Section C obtained information regarding the TAM antecedents by adapting Davis' (1989) PEOU and PU, and Moon and Kim's (2001) PP existing 5-point Likert scales. Section D consisted of questions relating to SST experience, adapting Akesson et al.'s (2014) existing 7-point semantic differential scale and Section E determined respondents' SST satisfaction, particularly chatbot satisfaction, by adapting Lin and Hsieh (2006) existing 7-point Likert scale.

To analyse the study's results, an exploratory factor analysis (EFA) used to uncover the dimensionality of all the scales used, before a regression analysis was performed to determine whether the TAM antecedents significantly predicted SST experience and whether SST experience predicted SST satisfaction when interacting with a chatbot. The Pearson correlation coefficient was used to characterise the linear correlation between the antecedents and to determine whether there was a positive, a negative or no relationship between these antecedents (Pallant 2016). Results indicating a $p \leq 0.05$ were considered statistically significant.

\section{Empirical findings}

More females (53.9\%) than males (46.1\%) participated in the study. Most respondents were between 18 and 35 years of age (92.4\%), held a diploma or university degree (54.4\%) and spoke English (46.1\%) at home.

English was followed by Zulu (12.8\%) and Sotho (11.2\%). Interestingly, nearly $10 \%$ of respondents indicated that they had never heard of a chatbot and $22.2 \%$ said they knew what it was, but had never interacted with a chatbot. These respondents were not included in the analysis. Those who had interacted with a chatbot, represented $66.9 \%(n=223)$ of the sample.

\section{Exploratory factor analysis, validity and reliability}

An EFA was performed to establish the validity of the measuring instrument and to determine the underlying dimensionality. Principal axis factoring with varimax rotation was used (Hair et al. 2014) and five factors were extracted based on investigating the Eigenvalue $(>1)$ criterion (Pallant 2016) that explained $74.28 \%$ of the overall variance. The Kaiser-Meyer-Olkin (KMO) measure of sampling adequacy was 0.851 (which is greater than the recommended 0.6) and the Bartlett's test of sphericity was significant at $p=0.000$ for all the factors (Pallant 2016). From these results it could be deduced that the data were appropriate for factor analysis after one item (SSTE3: How would you evaluate your experience with chatbots, Beneficial vs. Harmful [Djelassi et al. 2018]) was deleted from the SST experience scale. The item had to be deleted because of a low factor loading (0.4) and low communality (0.3), which increased the Cronbach's 
alpha (CA) value from 0.485 to 0.914 . Table 1 presents a summary of the extracted factors, number of items per factor, variance explained and CA value.

\section{Multiple regression}

The assumptions relating to sample size, multicollinearity and normality, the presence of outliers, linearity, and homoscedasticity of variance were investigated prior to performing the multiple regression and the authors ensured that these were not violated (Hair et al. 2014). Collinearity between the independent variables PEOU, PP and PU was evaluated by means of a variance inflation factor (VIF) where the values ranged from 1.858 (PU) and 1.768 (PEOU) to 1.472 $(\mathrm{PP})$, indicating a strong correlation between these variables and SST experience. Self-service technology experience revealed a VIF value of 1.000, also indicating a strong correlation with the dependent variable SST satisfaction. A multiple regression analysis was performed to determine whether the proposed technology antecedents (PEOU, PP, $\mathrm{PU})$ predict SST experience and whether SST experience predicts SST satisfaction.

The results of the multiple regression analysis indicated that PEOU ( $p \leq 0.01, \beta=0.232)$, PU $(p \leq 0.01, \beta=0.288)$ and PP $(p \leq 0.01, \beta=0.135)$ statistically significantly predicted SST experience, whilst SST experience ( $p \leq 0.01 ; \beta=0.838)$ statistically significantly predicted SST satisfaction. Of all the relationships tested, the relationship between SST experience and SST satisfaction ( $p \leq 0.01, \beta=0.838$ ) was the strongest indicating the important impact a chatbot user's experience will have on his or her satisfaction with the specific chatbot. The Pearson correlation statistic indicated that all hypotheses were positive, with PEOU $(r=0.469), \mathrm{PP}(r=0.394)$ and PU $(r=0.502)$ correlating with SST experience and SST experience $(r=0.522)$ correlating with SST satisfaction. Furthermore, the model summary indicated that the independent variables PEOU, PU and PP explained $30.2 \%$ of SST experience, and that SST experience explained $27.2 \%$ of SST satisfaction. Therefore, all the hypotheses of this study were accepted (Figure 2).

\section{Key contributions and recommendations}

In terms of the theoretical contributions, it should be observed that whereas previous research explored the relationship amongst PU, PEOU and PP on SSTs, this research did not specifically focus on chatbots (Abdullah et al. 2016).
Other studies have described the relationship between SST experience and SST satisfaction; however, their relationship with chatbots specifically was not investigated (Djelassi et al. 2018). Although the improvement of chatbot experience was investigated by Duijst (2017), the investigation was not within the context of SST satisfaction. Furthermore, limited research has been conducted on chatbots, specifically in South Africa; however, this was from the developer's point of view and not the customer's (Shawar \& Atwell 2007).

The interrelationships between the constructs as proposed in Figure 1 has not been explored within the services marketing previously, and therefore the services marketing literature is expanded through this research. Considering the lack of research on chatbot experience from an emerging African market perspective, this study contributes to the research from a consumer behaviour perspective. Whilst considering connectivity in an emerging market context, such as South Africa, the current lack of connectivity will provide future growth potential in this area. By the end of 2019 , less than $30 \%$ of Africa was connected to the Internet, compared with $82.5 \%$ of Europe and $76.7 \%$ of the United States of America (Johnson 2021). Poorer South Africans are yet to be connected and currently their only means is via a mobile handset that goes hand in hand with high data charges and at the time of this writing no nationwide measure was taken to make it more affordable (Cave 2020). The Competition Commission published a report at the end of December 2019, forcing cell phone companies to adjust pre-paid data prices as they are criticised for not assisting the poor, otherwise they will face prosecution (Shoba 2020). This pressure along with the available scope to grow Internet connectivity will have a positive impact on development and marketability of chatbots as they will be easily accessible in the future.

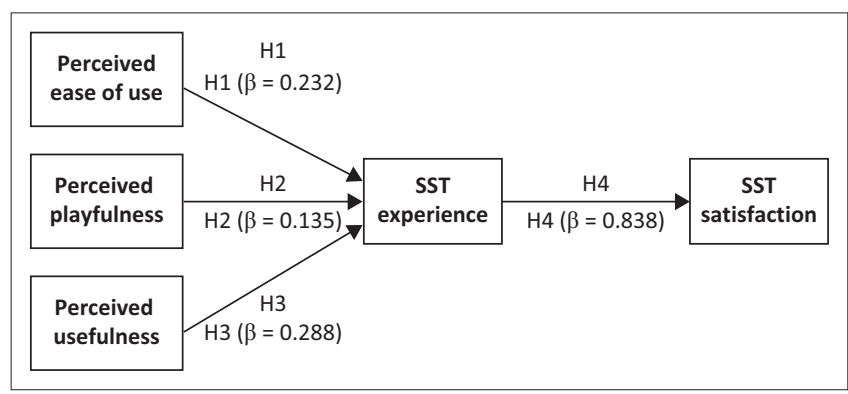

SST, self-service technology.

FIGURE 2: Final model and standardised coefficient.

TABLE 1: Exploratory factor analysis summary.

\begin{tabular}{lccccc}
\hline Factors extracted & Items $(\boldsymbol{n})$ & CA & $\begin{array}{c}\text { When an item is } \\
\text { deleted }\end{array}$ & $\begin{array}{c}\text { CA } \\
\text { Eigenvalue (\% of } \\
\text { variance) }\end{array}$ & $\begin{array}{c}\text { Variance explained } \\
\text { (Cumulative \%) }\end{array}$ \\
\hline Perceived ease of use (PEOU) & 5 & 0.863 & N/A & 0.863 & 44.0 \\
Perceived playfulness (PP) & 4 & 0.861 & N/A & 0.861 & 10.1 \\
Perceived usefulness (PU) & 6 & 0.922 & N/A & 0.922 & 9.4 \\
Self-service technology experience (SST E) (SST E item 3 deleted) & 4 & 0.485 & $3 \dagger$ & 0.914 & 6.3 \\
Self-service technology satisfaction (SST S) & 3 & 0.865 & N/A & 0.865 & 3.9 \\
\hline
\end{tabular}

N/A, not applicable; CA, Cronbach's alpha.

$\dagger$, SST experience was the only construct that indicated a CA value below 0.7. Because of a low factor loading (0.4) and a low communality (0.3), measurement scale item number 3 (SST E3: How would you evaluate your experience with chatbots, Beneficial vs Harmful (Djelassi et al. 2018) was deleted which increased the CA value to 0.914 and therefor SST E was retained for further analysis. 
This study set out to broaden the understanding of technology acceptance antecedents (PEOU, PP and PU), SST experience and SST satisfaction in an emerging market context. This purpose was achieved by establishing that these antecedents, as proposed in previous quantitative studies, do in fact predict chatbot experience and that chatbot experience predicts chatbot satisfaction.

Given the antecedents of technology acceptance, namely PEOU, PP and PU (Duijst 2017), this study confirmed that they predict chatbot experience (Bilgihan et al. 2016; Haung \& Liao 2015) and that customers' chatbot experience predicts their satisfaction with the chatbot (De Haan et al. 2018; Djelassi et al. 2018) in the context of an emerging market (South Africa). Whilst this study confirmed that PEOU, PP and PU predict chatbot experience, it further established that $\mathrm{PP}$ is of lesser importance as a predictor of positive experiences. Of the three antecedents, PU predicts chatbot experience the most profoundly, thus confirming Zarouali et al.'s (2018) study.

As more South Africans will be connected to the Internet by 2025, more opportunity will arise for organisations to implement chatbots and for customers to interact with them. From a managerial perspective, the following conclusions can be drawn. The results indicated that those who interacted with a chatbot, require chatbots to save them time and increase their productivity by allowing tasks to be completed effectively and with ease (Duijst 2017). Interacting with a chatbot should be as close as possible to the organic experience of talking to a 'real' person. Hence, the integration of voice recognition capabilities in chatbots can make them more human-like (Kayton 2018). Furthermore, customer service strategies should be put in place to ensure that when a chatbot is unable to handle a complex query, there is an option to easily connect with a real human agent. Ease of use can be further enhanced by making the chatbot available across various platforms and possibly offering multiple language options, specifically in a country such as South Africa with 11 official languages.

This research further emphasises the importance of customer experience. Whilst chatbots have many benefits, like reducing costs for the organisation, it is the improvements they make in customer experience that are impactful and valuable (Kannan \& Bernoff 2019). It is evident from the results of this study that 18- to 35-year-olds, who are more at ease with new technologies such as chatbots and therefore more likely to interact with them (Bizcommunity 2018), value chatbot experiences (Arnold 2018). Valuable experiences can be described as pleasant and favourable experiences with the chatbot, which provide the customer with benefits such as real-time engagement (Toader et al. 2020). Customer experience can therefore be improved through the value that is created by chatbot dialogues - in real time. This can be achieved by presenting the customer with next-best offers and recommendations, as identified using AI support, thus ensuring that these options are relevant to the customer
(Kreutzer \& Sirrenberg 2020). Experience of interacting with a chatbot will be further enhanced if it is easy to access $24 / 7$ when other options, for example, customer services are not available (Sanny et al. 2020). If a chatbot is unable to answer the query, there is the possibility that 'it' can contact you at a set time suitable to the customer.

As millennials have become more dependent on technology, it has become a priority to have information that is readily available and personalised and that provides them with the ability to control their own user experience (Brintia 2018). Whilst negative experience with a chatbot can lead to negative word-of-mouth and customers moving to competitors (Akesson et al. 2014), positive experience will lead to satisfied customers (De Haan et al. 2018; Djelassi et al. 2018). Satisfied customers are more likely to promote and recommend a product or service (Hemdi et al. 2016). For organisations to achieve satisfaction, marketers can improve customers' experience with SSTs by leveraging existing solutions through personalisation and customisation. A past study, for example, has found that changing a chatbot's gender can positively enhance experience and satisfaction whilst addressing only specific questions as directed by the customer interacting with the chatbot (Toader et al. 2020).

Product recommendations, as interpreted by chatbots analysing past searches and questions from the customer, can also build significant engagement and satisfaction for customers. Satisfaction can be further achieved by providing multichannel options for customers, allowing them to gain access to the same rank of service across all the platforms, which they may choose to engage with. This means providing access to the same chatbot function through the organisation's website, social media platforms and mobile applications. Organisations that offer multichannel options guarantee an experience that is consistent for customers, irrespective of the platform through which they may prefer to interact (Nguyen 2019).

\section{Conclusion}

Despite the adoption of chatbots, they are still just coming into existence and beginning to display signs of future potential. A study by Jain et al. (2018) found that the majority of chatbot users were first-time chatbot users and $84 \%$ of Internet users had not yet used a chatbot, thus indicating the growth potential of chatbots and warranting investigation to understand their impact more fully. Chatbots, or virtual assistants, have many benefits to organisations and the customer interacting with them. For the organisation they can foster engagement, save resources, differentiate the organisation, automate tasks, streamline activities, improve customer acquisition and retention and provide 'real-time' solutions - and because of AI's deep learning capabilities chatbots keep getting better. Chatbots help organisations to serve a larger number of customers with fewer resources, resulting in cost reduction for the company (Iqbal et al. 2018). Furthermore, it is believed that chatbots can be a more effective channel strategy than 
telephone and e-mail in handling multiple enquiries and requests parallel with other customer service channels, thereby increasing an organisation's efficiency and effectiveness (Brintia 2018; Kannan \& Bernoff 2019; Sanny et al. 2020; Toader et al. 2020).

It is evident from this study that chatbots affect both organisations and customers; however, with a specific focus on customers' interactions with chatbots, it has become clear that customers require chatbots to be useful and easy to use. They expect chatbots to accomplish their primary task and to outperform their app, search engine alternatives or website by offering diverse and (or) enhanced functionalities. For a chatbot to be useful, it must also communicate its functionalities and check for domain suitability (Jain et al. 2018). Customers interacting with chatbots want to access them wherever and whenever it is convenient to them (Iqbal et al. 2018). To South African millennials, chatbots offer many opportunities as active Internet users believe new technologies offer more opportunities than risks. Customers, specifically emerging market millennials, value experience and positive experiences will lead to satisfied customers who are beneficial to the sustainability, growth and prosperity of any organisation.

\section{Limitations and avenues for future research}

This study comes with limitations that should be considered when future research is conducted. The data collected for the study were based on millennials in South Africa, particularly in Gauteng province, which represents only one of the nine provinces in the country. A study collecting data from more provinces would be more representative of the entire South African population. As the study is classified as cross sectional, time constraints were imposed on the study. Future studies should focus on longitudinal research in order to better examine the links between the variables and investigate other possible variables that might arise.

\section{Acknowledgements}

The authors would like to acknowledge Dhlamini Busisiwe, Dlalisa Ayanda and Nke Matlhogonolo. All these students assisted with the data capturing and cleaning.

\section{Competing interests}

The authors have declared that no competing interests exist.

\section{Authors' contributions}

All authors contributed equally to this work.

\section{Ethical considerations}

The Institutional Review Board at a large Gauteng public university approved the research. The Ethical clearance code obtained: 2019SCiiS32.

\section{Funding information}

This research received no funding, no specific grant from any finding agency in the public, commercial or not-for-profit sectors.

\section{Data availability}

Data are the intellectual property of the University of Johannesburg and sharing might be considered if there is a case for it.

\section{Disclaimer}

The views and opinions expressed in this article are those of the authors and do not necessarily reflect the official policy or position of any affiliated agency of the authors.

\section{References}

Abdullah, F., Ward, R. \& Ahmen, E., 2016, 'Investigating the influence of the most commonly used external variables of TAM on students' PEOU and PU of e-portfolios', Computers in Human Behaviour 63, 75-90. https://doi.org/ 10.1016/j.chb.2016.05.014

Ahn, Y., Lee, B.C. \& Lee, S.K., 2020, 'Analysis of Korean millennials' travel expenditure patterns: An almost ideal demand system approach', Asia Pacific Journal of Tourism Research 25(1), 3-14. https://doi.org/10.1080/10941665.2019.1578810

Åkesson, M. \& Edvardsson, B., 2018, 'Customer roles from a self-service system perspective', International Journal of Quality and Service Sciences 10(2), 196-210. https://doi.org/10.1108/IJQSS-10-2017-0089

Akesson, M., Edvardsson, B. \& Tronvoll, B., 2014, 'Customer experience from a selfservice system perspective', Journal of Service Management 25(5), 677-698. $\mathrm{https} / / /$ doi.org/10.1108/JOSM-01-2013-0016

Arnold, A., 2018, 'How chatbots feed into millennials' need for instant gratification', Forbes, viewed 03 January 2020, from https://www.forbes.com.

Awa, H., Ojiabo, O. \& Emecheta, B., 2015, 'Integrating TAM, TPB and TOE frameworks and expanding their characteristic constructs for e-commerce adoption by SMEs', Journal of Science and Technology Policy Management 6(1), 76-94. https://doi. org/10.1108/JSTPM-04-2014-0012

Bilgihan, A., Kandampully, J. \& Zhang, T., 2016, 'Towards a unified customer experience in online shopping environments: Antecedents and outcomes', International Journal of Quality and Service Sciences 8(1), 102-119. https://doi.org/10.1108/ IJQSS-07-2015-0054

Bilgihan, A., Okumus, F., Nusair, K. \& Bujisic, M., 2014, 'Online experiences: Flow theory, measuring online customer experience in e-commerce and managerial implications for the lodging industry', Information Technology \& Tourism 14 49-71. https://doi.org/10.1007/s40558-013-0003-3

Bitner, M.J., Faranda, W.T., Hubbert, A.R. \& Zeithaml, V.A., 1997, 'Customer contributions and roles in service delivery', International Journal of Service Industry Management 8(3), 193-205. https://doi.org/10.1108/09564239710185398

Bizcommunity, 2018, '5 expectations of the African millennial consumer', CRM opinion Africa, Bizcommunity, viewed 03 January 2020, from https://www.bizcommunity. africa/Article/410/458/179653.html.

Brintia, 2018, 'Growing up with technology: The millennial's changing business', Brintia, viewed 05 January 2020, from https://www.brintia.com/growing-upwith-technology-the-millennials-changing-business/.

Cave, K., 2020, 'Staying connected in locked down South Africa', IDG Connect, viewed 17 April 2020, from https://www.idgconnect.com/article/3579035/stayingconnected-in-locked-down-south-africa.html.

Chatbots Life, 2019, 'Chatbot 2019 trends and stats with insider reports', Chatbots Life, viewed 06 May 2019, from https://collect.chat/blog/chatbots-trends-andstats-2019/.

Chen, H.-L., Widarso, G.V. \& Sutrisno, H., 2020, 'A chatBot for learning Chinese: Learning achievement and technology acceptance', Journal of Educational Computing Research 58(6), 1161-1189. https://doi.org/10.1177/0735633120929622

Conn, M., 2020, 'The pitfalls of chatbots for customer experience', Bizmag, viewed n.d., from https://bizmag.co.za/the-pitfalls-of-chatbots-for-customer-experience/.

Curran, J.M. \& Meuter, M.L., 2005, 'Self-service technology adoption: Comparing three technologies', Journal of Services Marketing 19(2), 103-113. https://doi. org/10.1108/08876040510591411

Dabholkar, P.A. \& Bagozzi, R.P., 2002, 'An attitudinal model of technology-based selfservice: Moderating effects of consumer traits and situational factors', Journal of the Academy of Marketing science 30(3), 184-201. https://doi.org/10.1177/ 00970302030003001

Davenport, T., Guha, A., Grewal, D. \& Bressgott, T., 2020, 'How artificial intelligence will change the future of marketing', Journal of the Academy of Marketing Science 48(1), 24-42. https://doi.org/10.1007/s11747-019-00696-0 
Davis, F.D., 1989, 'Perceived usefulness, perceived ease of use, and user acceptance of information technology', MIS Quarterly 13(3), 319-340. https://doi.org/ $10.2307 / 249008$

De Haan, H., Snijder, J., Van Nimwegen, C. \& Beun, R.J., 2018, 'Chatbot personality and customer satisfaction', Bachelor thesis, Utrecht University, viewed 06 April 2019 from https://www.scribd.com/document/472909794/Chatbot-Personality-andCustomer-Satisfaction-Bachelor-Thesis-Information-Sciences-Hayco-de-Haan.

Devaney, E., 2018, 'The 2018 state of chatbots report: How chatbots are reshaping online experiences', Drift, viewed 10 April 2019, from https://nextbigwhat.com/ chatbots-report-2018/.

Diaz, J.A., 2019, 'How to improve your customer experience using chatbots', We are marketing, viewed 06 May 2019, from https://www.wearemarketing.com/blog/.

Djelassi, S., Diallo, M.F. \& Zielke, S., 2018, 'How self-service technology experience evaluation affects waiting time and customer satisfaction? A moderated mediation model', Decision Support Systems 111, 38-47. https://doi.org/10.1016/j.dss 2018.04.004

Duijst, D., 2017, 'Can we improve the user experience of chatbots with personalisation?', Master's thesis, University of Amsterdam, viewed 05 May 2019 from https://www.researchgate.net/publication/318404775_Can_we_Improve_ the_User_Experience_of_Chatbots_with_Personalisation.

Feine, J., Morana, S. \& Gnewuch, U., 2019, 'Measuring service encounter satisfaction with customer service chatbots using sentiment analysis', in proceedings of the 14th International conference on Wirtschaftsinformatik (WI2019), Siegen, viewed 05 May 2019, from https://www.researchgate.net/publication/329917196 Measuring_Service_Encounter_Satisfaction_with_Customer_Service_Chatbots using_Sentiment_Analysis.

Gartner, 2018, Top strategic predictions for 2018 and beyond, viewed 03 January 2020, from https://www.gartner.com.

Gopalani, A. \& Shick, K., 2011, 'The service-enabled customer experience: A jumpstart to competitive advantage', Journal of Business Strategy 32(3), 4-12. https:// doi.org/10.1108/02756661111121947

Gunawan, D., Putri, F.P. \& Meidia, H., 2020, 'Bershca: Bringing chatbot into hotel industry in Indonesia', Telkomnika 18(2), 839-845. https://doi.org/10.12928/ telkomnika.v18i2.14841

Hair, J.F., Black, W.C., Babin, B.J. \& Anderson, R.E., 2014, Multivariate data analysis, 7th edn., Pearson, Harlow.

Hammoud, J., Bizri, R.M. \& El Baba, I., 2018, 'The impact of e-banking service quality on customer satisfaction: Evidence from the Lebanese banking sector', Sage Open 8(3), 1-12. https://doi.org/10.1177/2158244018790633

Haung, T.-L. \& Liao, S., 2015, 'A model of acceptance of augmented-reality interactive technology: The moderating role of cognitive innovativeness', Electronic Commerce Research 15(2), 269-295. https://doi.org/10.1007/s10660-014-9163-2

Hemdi, M.A., Rahman, S.A.S., Hanaflah, M.H. \& Adanan, A., 2016, 'Airport self-service check-in: The influence of technology readiness on customer satisfaction', in proceedings of the $3 \mathrm{rd}$ International hospitality and tourism conference and 2 nd International seminar on tourism, Indonesia, viewed 10 April 2019, from https:// www.researchgate.net/profile/Mohd-Hanafiah/publication/345789403_Airport self-service_check-in_The_influence_of_technology_readiness_on_customer_ satisfaction/links/5fb bdb2 192851c933f517e3f/Airport-self-service-check-in-Theinfluence-of-technology-readiness-on-customer-satisfaction.pdf.

Hsiao, C. \& Tang, K., 2014, 'Explaining undergraduates' behavior intention of e-textbook adoption: Empirical assessment of five theoretical models', Emerald Group Publishing Limited 32(1), 139-163. https://doi.org/10.1108/LHT-09-2013-0126

Iqbal, M.S., Hassan, M.U. \& Habibah, U., 2018, 'Impact of self-service technology (SST) service quality on customer loyalty and behavioral intention: The mediating role of customer satisfaction', Congent Business \& Management 5, 1. https://doi.org/ 10.1080/23311975.2018.1423770

Jain, M., Kumar, P., Kota, R. \& Patel, S.N., 2018. 'Evaluation and informing the design of chatbots', Session 18: Interacting with Conversational Agents of the DIS
(Designing Interactive Systems) 2018 conference, June 9-13, 2018, Hong Kong, pp. 895-906.

Johnson, J., 2021, 'Global Internet penetration rate 2009-2019, by region', Statista, 05 February, 2021, viewed n.d., from https://www.statista.com/statistics/265149/ internet-penetration-rate-by-region/.

Kaczorowska-Spychalska, D., 2019, 'How chatbots influence marketing', Management 23(1), 251-270. https://doi.org/10.2478/manment-2019-0015

Kannan, P.V. \& Bernoff, J., 2019, 'Does your company really need a chatbot?', Harvard Business Review, Digital articles, pp. 2-6, viewed 28 March 2019, from https:// hbr.org.

Kar, R. \& Haldar, R., 2016, 'Applying chatbots to the internet of things: Opportunities and architectural elements', arXiv preprint arXiv:1611.03799.

Kayton, D., 2018, 'Don't talk to me, talk to my chatbot', BizCommunity, viewed 02December2019, from https://www.bizcommunity.com/Article/196/16/181969. html.
Kreutzer, R.T. \& Sirrenberg M., 2020, 'Fields of application of artificial intelligence Customer service, marketing and sales', in Understanding artificial intelligence: Management for professionals, pp. 105-154, Springer, Cham.

Lin, J.S.C. \& Hsieh, P.L., 2006, 'The role of technology readiness in customers' perception and adoption of self-service technologies', International Journal of Service Industry Management 17(5), 497-517. https://doi.org/10.1108/ 09564230610689795

Malhotra, N.K., 2012, Basic marketing research: Integration of social media, 4th edn., Pearson, s.l.

Mkpojiogu, E.O. \& Hashim, N.L., 2016, 'Understanding the relationship between Kano model's customer satisfaction scores and self-stated requirements importance', Springer Plus 5(1), 197. https://doi.org/10.1186/s40064-016-1860-y

Moon, J.W. \& Kim, Y.G., 2001, 'Extending the TAM for the world-wide-web context', Information and Management 38(4), 217-230. https://doi.org/10.1016/S03787206(00)00061-6

Mosavi, S.M., Sangari, M.S. \& Keramati, A., 2018, 'An integrative framework for customer switching behavior', The Service Industries Journal 38(15-16), 10671094. https://doi.org/10.1080/02642069.2018.1428955

Nguyen, D., 2019, 'Influences of multi-channel distribution related to consumer buying behavior and profits growth rate', thesis, Vaasan Ammattikorkeakoulu University of Applied Sciences, viewed n.d., from https://www.theseus.fi/ bitstream/handle/10024/167398/Dung\%20Nguyen-e1601095-\%20Thesis. pdf? sequence $=2$ \&isAllowed $=y$.

Oliver, R.L., 2014, Satisfaction: A behavioural perspective on the consumer, 2nd edn., Routledge, New York

Padilla-Meléndez, A., Del Aguila-Obra, A.R. \& Garrido-Moreno, A., 2013, 'Perceived playfulness, gender differences and technology acceptance model in a blended learning scenario', Computers \& Education 63, 306-317. https://doi.org/10.1016/j. compedu.2012.12.014

Pallant, J., 2016, SPSS survival manual: A step by step guide to data analysis using SPSS, 6th edn., McGraw-Hill Education, Berkshire.

Rese, A., Ganster, L. \& Baier, D., 2020, 'Chatbots in retailers' customer communication: How to measure their acceptance?', Journal of Retailing and Consumer Services 56(1), 102176. https://doi.org/10.1016/j.jretconser.2020.102176

Rust, R. \& Oliver, R.L., 1994, 'Service quality insights and managerial implications from the frontier', in R.T. Rust \& R.L. Oliver (eds.), Service quality new directions in theory and practice, pp. 1-19, Sage, Thousand Oaks, CA.

Ryding, D., 2010, 'The impact of new technologies on customer satisfaction and business to business customer relationships: Evidence from the soft drinks industry', Journal of Retailing and Consumer Services 17(3), 224-228. https://doi. org/10.1016/j.jretconser.2010.03.008

Sanny, L., Susastra, A., Roberts, C. \& Yusramdaleni, R., 2020, 'The analysis of customer satisfaction factors which influence chatbot acceptance in Indonesia', Management Science Letters 10(6), 1225-1232. https://doi.org/10.5267/j.msl.2019.11.036

Saunders, M.N.K., Lewis, P. \& Thornhill, A., 2016, Research methods for business students, Pearson Education Limited, London.

Shawar, B.A. \& Atwell, E., 2007, 'Chatbots: Are they really useful?', LDV Forum 22(1), 29-49.

Shoba, S., 2020, 'Are mobile network providers doing enough to keep South Africans connected?', Daily Maverick, 18 March 2020, viewed 5 February 2021, from https://www.dailymaverick.co.za/.

Taulli, T., 2019, 'What you need to know about chatbots', Forbes April 21, 2019, viewed 12 December 2019 from https://www.forbes.com.

Toader, D.C., Boca, G., Toader, R., Măcelaru, M., Toader, C., Ighian, D. et al., 2020, 'The effect of social presence and chatbot errors on trust', Sustainability 12(1), 256. https://doi.org/10.3390/su12010256

Van de Sand, F., Frison, A.K., Zotz, P., Riener, A. \& Holl, K., 2020, User experience Is brand experience, Springer, Cham.

Verma, M., 2019, 'Data-oriented and machine learning technologies in FinTech', FinTechs and an evolving ecosystem, vol. 1, viewed 12 December 2019, from https://www.idrbt.ac.in/assets/publications/Staff\%20Papers/20190805_FT. pdf\#page=3.

Wang, C., Harris, J. \& Patterson, P., 2013, 'The roles of habit, self-efficacy, and satisfaction in driving continued use of self-service technologies: A longitudinal study', Journal of Service Research 16(3), 400-414. https://doi.org/10.1177/ 1094670512473200

Zarouali, B., Broeck, E., Walrave, M. \& Poels, K., 2018, 'Predicting consumer responses to a chatbot on Facebook', Cyberpsychology, Behavior, and Social Networking 21(8), 491-497. https://doi.org/10.1089/cyber.2017.0518

Zeithaml, V.A., Bitner, M.J. \& Gremler, D.D., 2009, Services marketing: Integrating customer focus across the firm, 5th edn., McGraw-Hill Irwin, New York. 